\title{
Research Article \\ Solar Hybrid System Component Study in Low Concentrated Sunlight
}

\author{
Petru A. Cotfas (iD) and Daniel T. Cotfas \\ Department of Electronics and Computers, Faculty of Electrical Engineering and Computer Science, Transilvania University \\ of Brasov, 500036, Romania \\ Correspondence should be addressed to Petru A. Cotfas; pcotfas@unitbv.ro
}

Received 30 October 2020; Revised 22 March 2021; Accepted 16 April 2021; Published 29 April 2021

Academic Editor: Mohammad Alghoul

Copyright (c) 2021 Petru A. Cotfas and Daniel T. Cotfas. This is an open access article distributed under the Creative Commons Attribution License, which permits unrestricted use, distribution, and reproduction in any medium, provided the original work is properly cited.

\begin{abstract}
The solar energy is increasingly used as a renewable energy source. Raising the efficiency of energy conversion from solar to useful energy (electric and thermal) represents an important research direction in the renewable energy domain. Using hybrid systems for electric and thermal energy cogeneration can be a solution. In this study, a hybrid system (HS) is designed, manufactured, implemented, and experimentally tested under concentrated sunlight with a concentration ratio of 25 suns, obtained using a Fresnel lens as a sunlight concentrator. The HS comprises of four concentrated photovoltaic cells (CPVs), four thermoelectric generators (TEGs), and a solar thermal collector (STC). The HS is studied in three configurations of the exposed surface: only the CPV active area, the CPV active area with ceramic support, and the CPV active area with ceramic support covered with graphite sheet. Results reveal that the efficiency of each system component is affected by the exposed surface. If the efficiencies of the CPVs decrease from $32.3 \%$ to $30.8 \%$ from the first configuration to the last one, the efficiencies of TEGs and STC increase from $0.12 \%$ to 0.44 and from $26.3 \%$ to $52.0 \%$, respectively. Increasing the concentration ratio from 25 to 33 suns, the power of the CPVs increases with almost $31 \%$, but the efficiency decreases slightly, instead the efficiencies of the TEGs and STC increase.
\end{abstract}

\section{Introduction}

Nowadays, renewable energy sources provide an important part of the total energy used worldwide. In order to increase the usability of renewable energy sources however, their efficiency needs to be improved. Such a method of increasing efficiency is the use of hybridisation, and such a hybrid system (HS) can be assembled from a photovoltaic cell (PV) with a thermoelectric generator (TEG), a PV with a solar thermal collector (STC), or PV-TEG-STC. The PV efficiency decreases with the increase of its temperature. The multijunction cell conversion efficiency in high concentration ratio can reach over $45 \%$ [1]. The solar absorbance of a PV has a range from $80 \%$ up to $93 \%$ [2], which means that a large percent of the sunlight is converted into heat, which increases the PV temperature. There are many solutions used for cooling the PVs [3, 4], and the ones most widely used being based on water cooling systems, such as water spraying on the PV surface [5], forced water circulation through thermal collect- ing pipes attached to the back of the PV module $[6,7]$ forming a PV/STC system and water immersion of the PV [8]. There are PV cooling systems based on air streams $[9,10]$ or based on thermoelectric coolers [11]. Recent studies based on numerical [12] and experimental [13] approaches are focused on passive cooling of PV panels. In [13], a passive air cooling was implemented based on aluminium fins leading to an increasing in the power yield with approximately $5 \%$. The solutions mentioned in $[5,8-13]$ are based on removing the thermal energy from the PV and eliminating in the environment without using it. Instead of eliminating the thermal energy, another approach is to use it. Based on this approach, a solution is to use the TEG as an electrical energy cogenerator, based on the temperature differences between PV and STC and using the STC as a thermal energy source. Such a system was studied in natural conditions by Cotfas et al. [14] showing that the output power of the PV integrated in the HS increased with more than $11 \%$ due to its temperature decreases. An important conclusion that 
resulted from this study is that the stabilization time for the studied HS configurations was around $7 \mathrm{~min}$. The effect of integrating a TEG in a HS could be negative due to its thermal resistance that is introduced between PV and the cooling system. There are many studies about the optimization of the HS from the perspectives of the material, geometry, thermal, and electrical connection. Li et al. [15] analysed a PV/TEG HS based on the geometrical parameters of the TEG, solar irradiance, and the cold side temperature, and they reported that the overall efficiency of the HS shown a proportional dependence with the cross-sectional area of the TEG and inversely proportional dependence with the height of the TEG and with the cold side temperature.

Rezania and Rosendahl [16] showed that a TEG used between the concentrated photovoltaic cell (CPV) and a heatsink increases the thermal resistance, which conducts to a higher temperature and consequently the CPV efficiency decreases. However, the overall system efficiency is enhanced due to the electrical cogeneration of both CPV and TEG. Kil et al. [17] showed that the total efficiency of the CPV/STC systems becomes higher than of a single CPV if the concentration ratio is higher than 35 suns. Liao et al. [18] describe a theoretical study of a PV/TEG system in low concentration ratio offering some criteria for an optimal design of such a system. According to this study, the PV/TEG design should consider the concentration ratio and the current through system components. Saeedi et al. [19] show that in a PV/STC system, the water flow rate can affect the performance of the system. A change in the water flow rate from $0.001 \mathrm{~kg} / \mathrm{s}$ to $0.044 \mathrm{~kg} / \mathrm{s}$ increases the efficiency of the system from approximately $17 \%$ to the optimum value of $21.56 \%$.

In concentrated sunlight, the cooling system for the $\mathrm{PV}$ is mandatory; therefore, using the CPV/TEG/STC system as a hybrid energy source becomes a feasible approach. A comprehensive review regarding the CPV/STC systems used in concentrated light covering the aspects as components design, heat transfer medium, applications, and economics was done by George et al. [20]. They found that the contradictory requirements of the components from electrical and thermal efficiency point of view could affect the HS efficiency without components optimization. At the same time, different parameters of the fluid used (like mass flow rate, density, viscosity, time, and desired temperature) can affect the performances of the thermal components.

The concentrated sunlight can be obtained using different techniques: there are sunlight concentrators based on parabolic reflectors, heliostats, Fresnel reflectors, or Fresnel lens with different shapes $[21,22]$. For HSs, these concentrators could be with or without spectral beam splitter [23].

Yazdanifard et al. [24] studied the effect of the flow regime, the length and diameter of the used pipes, and the nanofluids used as working fluids for a parabolic trough a CPV/STC system through simulation and compared the results with a flat PV/STC system. They found that the laminar or turbulent flow regime can affect the total energy efficiency of the system. The combination of the CPV/STC and TEG was studied in [25] through simulation and validated through experiment. For light concentration, a parabolic trough concentrator was used. Riahi et al. found that the elec- trical efficiency of the CPV/TEG/STC was enhanced by $7.46 \%$ in comparison to the CPV/STC. Also, in this paper, it was estimated that the annual electric energy generated by the CPV/TEG/STC system could be increased by $359 \mathrm{kWh}$ due to the TEG electrical cogeneration. Mahmoudinezhad et al. [26] studied the transient behaviour of a CPVTEG system in low concentration light ratio using numerical simulation and validation through a solar simulator. In transient conditions, the response of the CPV is rapid; instead, the TEG response is slower due to the thermal capacity and thermal resistance. Due to this behaviour, the TEG as component of the HS represents a way to stabilize the overall power output of HS.

The configuration of the HS is also very important. HS studied by [25] proposed to have two systems, a CPV/STC and a TEGS/STC which are placed side by side. This configuration exploits the maximum irradiance for both CPV and TEG but double the surface of the HS. Mohammadnia et al. [27] developed a model for a HS compose of CPV, TEG, and Stirling engine using a parabolic solar dish concentrator and a beam splitter. They found that overall conversion efficiency of the HS was $21.8 \%$ at 455.8 suns. Other approach is to place all three components of the HS in sandwich structure (one over the other). Each time a TEG is used, a heat sink should be placed on the cold side of TEG in order to remove the heat. During the study of the transient behaviour of the CPV/TEG HS [26, 28], the temperature of the TEG cold side varies up $10^{\circ} \mathrm{C}$ even while using water cooled heat sink. Therefore, instead of dissipating the heat, it can be converted in useful thermal energy. The sandwich approach was adopted in [29], in artificial conditions, in [14], under natural light, and in [30], under concentrated light using a solar simulator.

For HS, a key factor is the thermal management of high system performance. In analysing the abovementioned studies for HS, the absorbance of the exposed surface to the sun is not studied in depth. In this paper, we focused on studying the CPV/TEG/STC HS, with sandwich structure, in real conditions, considering different surface exposure to determine the effect of heat absorption on efficiency of each HS component. This aspect should be studied due to the opposing requirements of the $\mathrm{HS}$ components. While the $\mathrm{CPV}$ requires low temperature, the other components require large temperature differences, so high temperatures are needed. We consider the cases of exposing to the irradiance only the active CPV area and the entire CPVs' area including the support, and in the third case, we use a heat absorber. As concentrator, a plan Fresnel lens is used that allows us to study the HS at low concentrated sun ratio, according to [31], where three sunlight concentrator classes are considered: low concentration class with the rage of 1-40 suns, medium concentration class with the range of 40-300 suns, and high concentration class with the range of 300-2000 suns.

The rest of this paper is structured as follows: the second section describes all aspects regarding the experimental setup that include the structure of the HS, the sun tracker used, the sun concentrator, and the developed measurement systems used to characterize the HS components, the third section is dedicated to results and discussions that cover the 
measurements and analysis of all three HS components, and the fourth section is dedicated to conclusions. The results obtained through this experimental study can be used as references for HS design from the heat absorption optimization point of view.

\section{Experimental Setup}

2.1. Hybrid System. The hybrid system (HS) is built as a sandwich structure formed by four concentrated photovoltaic cells (CPVs), four thermoelectric generators (TEGs) placed between the CPVs, and a solar flat thermal collector (STC) (see Figure 1). The entire HS was placed into a thermal insolating box leaving opened only the top surface.

The CPVs are concentrating triple-junction photovoltaic cells (InGaP/InGaAs/Ge) which are designed for working in concentrated sunlight, manufactured by SolAero Technologies [32]. The CPV characteristic parameters are shown in Table 1 . We used four CPVs with the active area of $1 \mathrm{~cm}^{2}$, placed on a $2 \mathrm{~cm} \times 2 \mathrm{~cm} \times 1 \mathrm{~mm}$ ceramic support $\left(\mathrm{Al}_{2} \mathrm{O}_{3}\right)$ that has direct bonded copper with $\mathrm{Au} / \mathrm{Ni}$ surface plating. The CPVs are connected two by two in series.

TEGs are $\mathrm{Bi}_{2} \mathrm{Te}_{3}$ type, manufactured by Stonecold, model TEC1-12710 [33], and all four are connected in series. The TEG characteristic parameters are shown in Table 1.

The STC is made from a copper block milled in an interdigitated channel shape. The size of the STC is $8 \mathrm{~cm} \times 8 \mathrm{~cm}$ $\times 1 \mathrm{~cm}$.

The four CPVs are placed on a cooper plate using a thermal conductive double adhesive tape with thermal conductivity $2.5 \mathrm{~W} / \mathrm{m} \bullet \mathrm{K}$. The copper plate ( $2 \mathrm{~mm}$ thick) is used for uniform heat distribution on the TEGs' top surface and also in order to have space for placing the thermocouples on the TEGs' surface (into milled channels in the copper plate). The thermal connections between TEGs' surfaces and STC and cooper plate are assured with a thermal conductive paste with the thermal conductivity of $3.8 \mathrm{~W} / \mathrm{m} \bullet \mathrm{K}$.

2.2. Sun Tracker. In order to concentrate the sunlight, the system was designed to follow the sun's movement. Hence, a sun tracker was implemented based on a J-PT-1008D-1 device, manufactured by JEC Electronics Technology, that has two degrees of freedom. The J-PT-1008D-1 device has the horizontal rotational angle of $356^{\circ}$ and the vertical rotational angle of $\pm 70^{\circ}$. Two PD30 optical encoders with 1000PPR were added to the J-PT-1008D-1 device for implementing a closed loop control for the sun tracker. The sun tracker is controlled using a NI myRIO device in which a mathematical algorithm was implemented.

2.3. Sunlight Concentrator (SLC). The SLC is built along a Fresnel lens with the size of $33 \mathrm{~cm} \times 33 \mathrm{~cm}$ made from polymethyl-methacrylate. The optical efficiency of the used Fresnel lens, $\eta_{\mathrm{FL}}$, is $83 \%$ [34]. The Fresnel lens is fixed on the main support using four threaded rods which allow modifying the distance between the Fresnel lens and the hybrid system (HS). The HS is placed on a secondary support that can be moved towards the Fresnel lens using a linear actuator driven by a stepper motor.
2.4. Measurement Systems. The measurement system diagram is shown in Figure 2. For measuring the important parameters of the HS, a NI cRIO 9074 platform with dedicated current, voltage, and temperature modules was used together with a self-designed electronic load, EL. The EL was developed based on the variation of a prepolarized capacitor impedance during the discharging/charging process and was used for measuring the I-V characteristics of the CPVs and TEG arrays. A simplified one channel schemata of the EL is shown in Figure 2. In the first stage, the switch connects the capacitor $\mathrm{C}$ to the voltage source $\mathrm{V}$ through the resistance $\mathrm{R}$ and it is negatively charged. In the second stage, the capacitor is connected through the switch $\mathrm{S}$ to the PV. In this stage, $\mathrm{C}$ is discharging on the PV and then is positively charging from the PV. In this manner, the influence of circuit resistance is eliminated assuring that the entire $\mathrm{I}-\mathrm{V}$ characteristic is obtained (from Isc to Voc). The temperature measurements are done with K-type thermocouples, which are placed on the top of each CPV support, between $\mathrm{Cu}$ plate and TEG, between TEG and STC, and at inlet and outlet of the STC.

The I/O modules on NI cRIO used for measurements were as follows: the NI 9215 voltage input module with $\pm 10 \mathrm{~V}$ input range and 16-bit resolution, NI 9225 current input module with $5 \mathrm{~A}_{\mathrm{RMS}}$ input range and 24-bit resolution, and NI 2013 and NI 9211 modules dedicated for temperature measurements based on thermocouples. The two temperature measurement modules have $78.125 \mathrm{mV}$ and $\pm 80 \mathrm{mV}$ input range, respectively, and 24-bit resolution. The accuracies of the used modules are as follows: for voltage module is $0.2 \%$, for current module $\pm 0.37 \%$, and for the temperature measurements less than $0.07^{\circ} \mathrm{C}$.

The water flow is measured with the FCH-m-POM-LC flowmeter which has an accuracy of $2 \%$. The solar irradiance is measured using the SPN1 Delta T pyranometer that offers information about global and diffuse irradiances. Using the two irradiances, the direct irradiance can be calculated. The SPN1 has a resolution of $0.6 \mathrm{~W} / \mathrm{m}^{2}$ and an uncertainty of $5 \%$.

The software applications for measuring, controlling, and data analysis were developed using NI LabVIEW. The entire system is shown in Figure 3. More details about the experimental system are presented in [35]. In order to minimize the errors due to the electronic noise on the system, a rectangular smoothing algorithm was applied with a smooth width of 75 points for voltage and current measurements and a smooth width of 3 points for temperature measurements.

The flow chart of the measurements is shown in Figure 4. The measurement procedure has the following structure:

(i) At the beginning, the PC synchronizes the clocks of the NI cRIO and NI myRIO devices with the PC clock. Then, the sun tracker is moved to the reference position (azimuth and altitude angles equal to zero)

(ii) It is verified if the time is in the day interval. In the true case, the sun tracker is moved to the sun position. The system waits for a predefined time $t_{W}$. Then, NI cRIO controls the three channels of EL for measuring the I$\mathrm{V}$ characteristics of the two CPV arrays (two channels) 


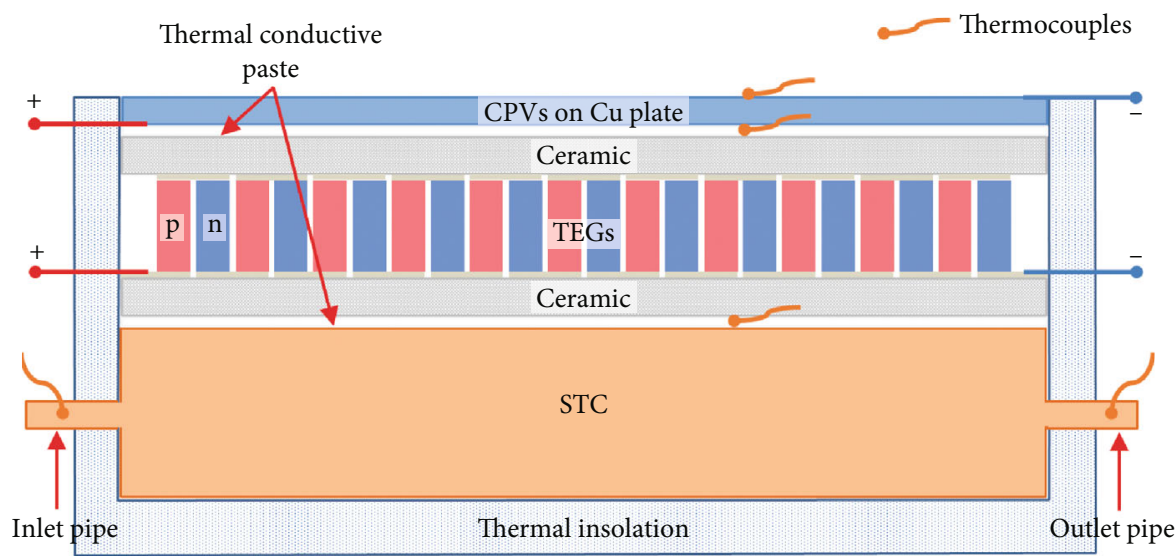

FIGURE 1: HS structure.

TABle 1: The CPV and TEG parameters according to their datasheet.

\begin{tabular}{|c|c|c|c|c|c|c|}
\hline HS components & $\begin{array}{l}\text { Dimensions per } \\
\text { device }\end{array}$ & $\begin{array}{l}\text { Efficiency } \\
\quad(\%)\end{array}$ & $\begin{array}{l}\text { Short circuit } \\
\text { current-Isc (A) }\end{array}$ & $\begin{array}{c}\text { Open circuit } \\
\text { voltage-Voc }(\mathrm{V})\end{array}$ & $\begin{array}{c}\text { Maximum } \\
\text { current-Imp (A) }\end{array}$ & $\begin{array}{l}\text { Maximum voltage- } \\
\operatorname{Vmp}(\mathrm{V})\end{array}$ \\
\hline \multirow[t]{2}{*}{$\begin{array}{l}\mathrm{CPV} \text { at } 500 \text { suns } \\
\text { and } 25^{\circ} \mathrm{C}\end{array}$} & $1 \mathrm{~cm} \times 1 \mathrm{~cm}$ & 39.6 & 6.48 & 3.19 & 6.34 & 2.76 \\
\hline & & $\begin{array}{l}\text { No. of } \\
\text { couples }\end{array}$ & $\begin{array}{c}\text { Internal resistance } \\
(\Omega)\end{array}$ & $\begin{array}{c}\text { Resistivity at } 25^{\circ} \mathrm{C} \\
(\Omega \mathrm{m})\end{array}$ & \multicolumn{2}{|c|}{$\begin{array}{c}\text { Seebeck coefficient of a thermoelectric } \\
\text { element }(\mu \mathrm{V} / \mathrm{K})\end{array}$} \\
\hline TEGs & $4 \mathrm{~cm} \times 4 \mathrm{~cm} \times 3.3 \mathrm{~mm}$ & 127 & 1.08 & $1.67 \times 10^{-5}$ & \multicolumn{2}{|c|}{116} \\
\hline
\end{tabular}

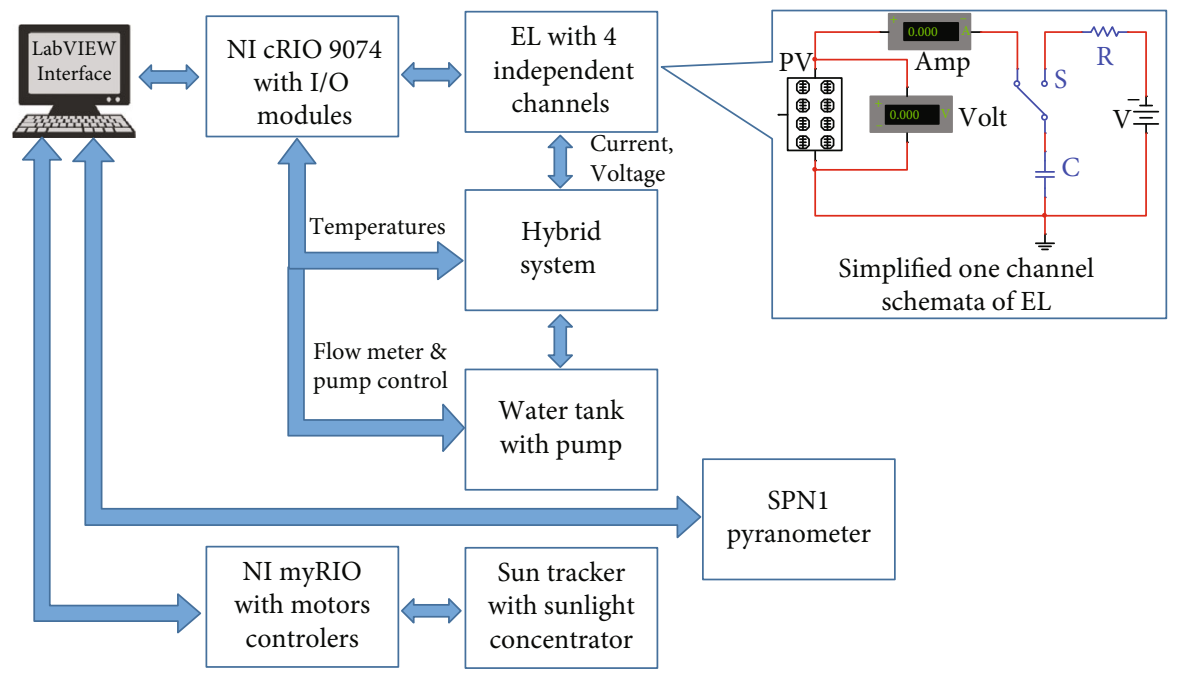

Figure 2: The system diagram.

and the TEG array (one channel). At the same time, all temperatures and the water flow are measured. The data for irradiance is obtained through the serial communication between PC and SPN1

(iii) All data are saved on the NI cRIO and PC HDDs, respectively

(iv) The system waits for a predefined measuring time, and then, the procedure is repeated, without initialization stage
All saved data are transferred to the PC and using a NI LabVIEW application are postprocessed and analysed.

\section{Results and Discussions}

The system was tested in natural conditions in the mountain city Brasov, Romania (lat: $45.648^{\circ}$ and long: $25.606^{\circ}$ ), having $500 \mathrm{~m}$ altitude. The system was placed on the roof of our university building for assuring the free shadow and reflection area. During the tests, sunny and partial sunny climate 


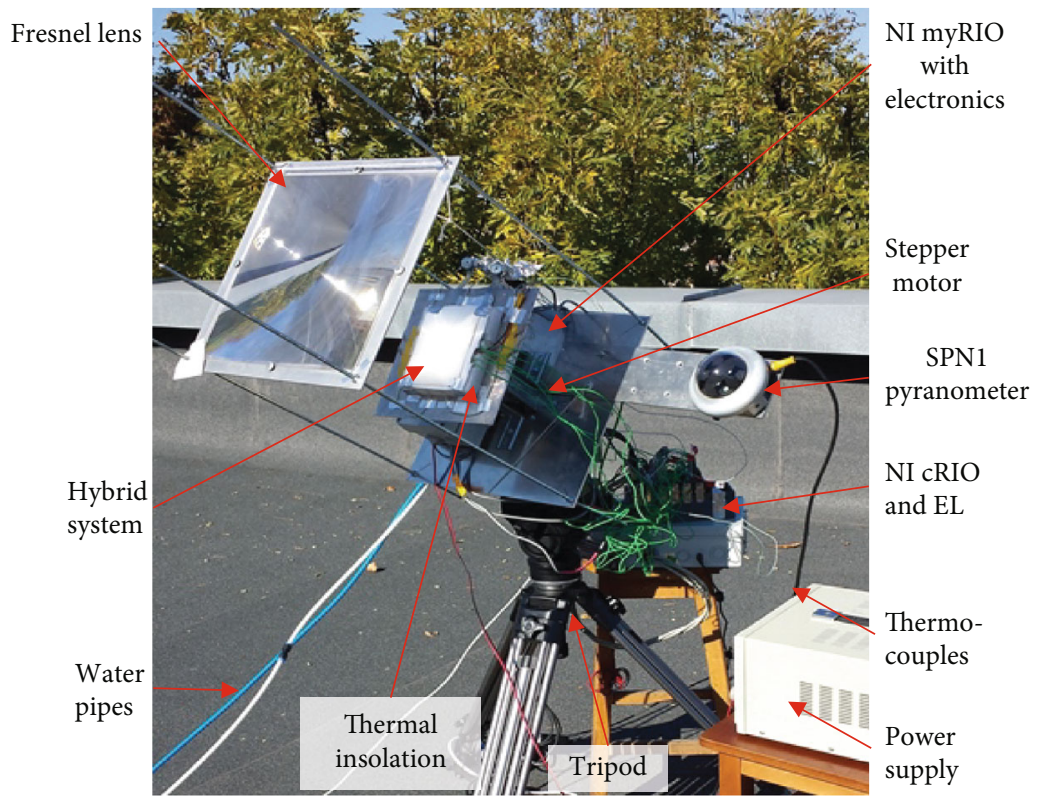

Figure 3: Experimental system.

conditions were present. The range of the irradiance level obtained with the developed system ranges from 5 to 56 suns on a $4 \mathrm{~cm} \times 4 \mathrm{~cm}$ area. The size of the illumination spot used for testing the system was $6 \mathrm{~cm} \times 6 \mathrm{~cm}$ for which the concentration ratio becomes 25 suns including the Fresnel lens optical efficiency. With this configuration, the uniformity of the $\mathrm{CPV}$ illumination is ensured.

The HS was covered with an alumina sheet for thermal protection, having three configurations:

(1) Only the active area of CPVs was kept uncovered (with alumina cross, WAC, Figure 5(a)). The exposed area is $4 \mathrm{~cm}^{2}$. In this case, the thermal energy that can be used by TEG and STC is the difference between the total energy absorbed by the CPVs and the energy converted in electricity

(2) The CPV support area was exposed, which is $16 \mathrm{~cm}^{2}$ (without alumina cross, WoAC, Figure 5(b)). In this case the usable thermal energy is increased by the support absorption

(3) The ceramic support of the CPVs was covered with a graphite sheet for better thermal absorption (with graphite sheet, WGS, Figure 5(c)). In this case, using the graphite sheet leads to the increasing of the thermal energy absorption by the system

The three configurations were selected in order to analyse the effect of the heat absorption on efficiency of each HS component. In the three surfaces having different heat absorption coefficients, the heat absorption is different so the working temperature of each component of HS will be modified. Due to the fact that thermal management of the system represents a very important factor in the overall efficiency of HS (CPV requires small temperature, while the TEG and STC require high temperature), using these three cases, it was possible to study how the heat absorption affects the HS efficiency.

The water flow rate for tests through the STC was set at $0.4 \mathrm{~L} / \mathrm{min}$. The electric power and the efficiency of the CPVs and TEGs were determined based on the I-V characteristics. The efficiency of the STC was calculated based on the inlet and outlet water temperatures and the incident irradiance.

3.1. CPV Analysis. The CPV I-V characteristics in concentrated and nonconcentrated sunlight were measured using the NI cRIO platform and the self-designed EL. Figure 6 illustrates the I-V and P-V characteristics for one array of CPVs in concentrated (25 suns) and nonconcentrated sunlight (the current and power of the CPVs are multiply by 20 in Figure 6). In nonconcentrated sunlight (without Fresnel lens), the maximum power generated by one CPV array was $51 \mathrm{~mW}$ obtained at an irradiance of $1000 \mathrm{~W} / \mathrm{m}^{2}$.

The CPV efficiency is calculated according to the following equation:

$$
\eta_{\mathrm{CPV}}=\frac{P_{\mathrm{CPV}}}{A_{\mathrm{CPV}} \cdot G} 100 \%,
$$

where $\eta_{\mathrm{CPV}}$ is the CPV electrical efficiency, $P_{\mathrm{CPV}}$ is the electric power of the CPVs $(\mathrm{W}), A_{\mathrm{CPV}}$ is the active area of CPVs $\left(\mathrm{m}^{2}\right)$, and $G$ is the irradiance $\left(\mathrm{W} / \mathrm{m}^{2}\right)$. Based on Equation (1), the CPV efficiency obtained was $25.5 \%$, with $P_{\mathrm{CPV}}=51 \mathrm{~mW}$, $A_{\mathrm{CPV}}=2 \mathrm{~cm}^{2}$ (the area of one CPV array), and $G=1000$ $\mathrm{W} / \mathrm{m}^{2}$.

Figure 7 shows the CPV electric power generated in concentrated sunlight of 25 suns. The average power of all four $\mathrm{CPVs}$ was around $3.1 \mathrm{~W}$. The average temperature variation of all CPVs and the direct sun irradiance measured in the plan of HS are presented in Figures 8 and 9. One can observe that the maximum temperature of the CPVs was obtained using the WGS configuration, and it was around $52^{\circ} \mathrm{C}$, 


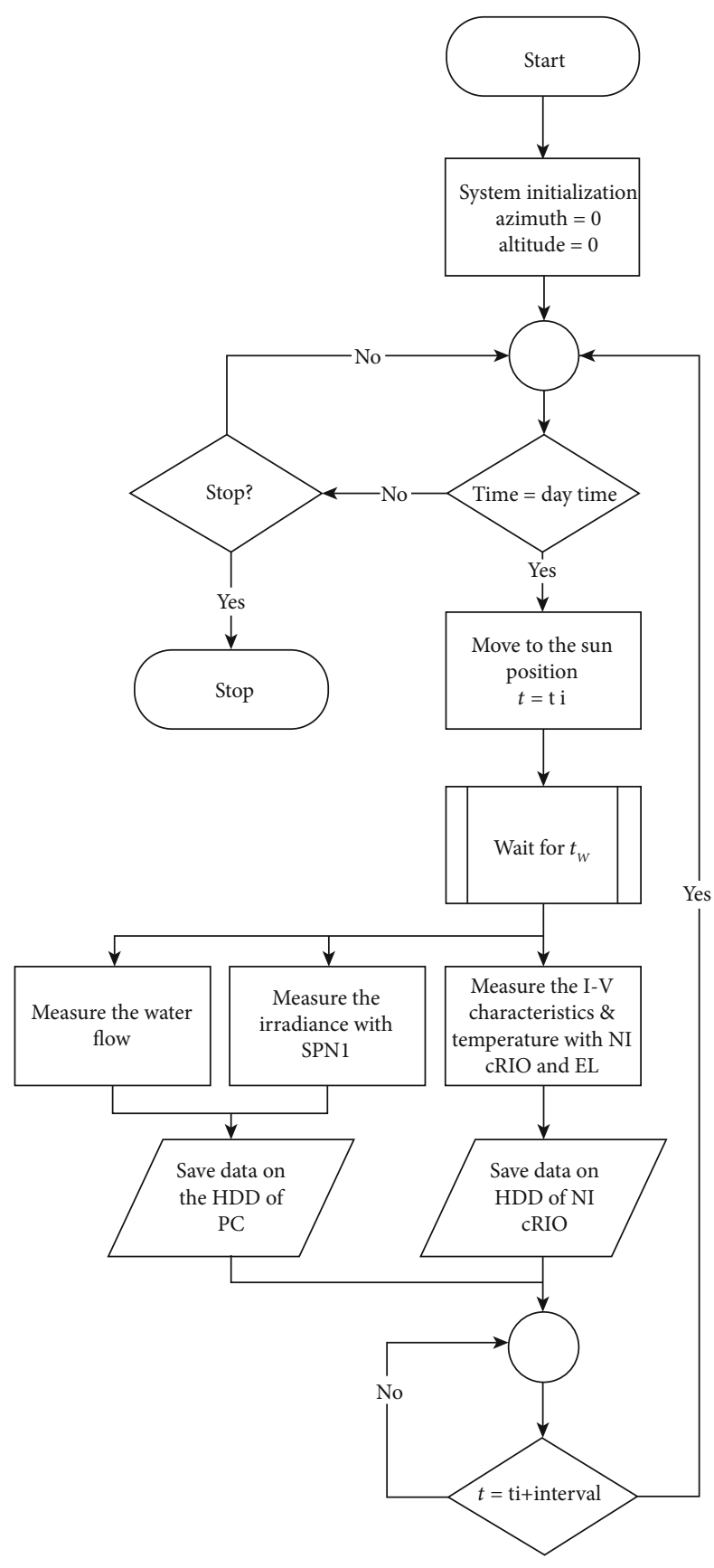

Figure 4: The flow chart of the system operation and measurement.

because of the heat absorption of the graphite sheet. In the case of the WAC configuration, the temperature of the CPVs is the smallest one, around $35^{\circ} \mathrm{C}$, because of the alumina shield. The measurements were done during three days with almost the same irradiance in July.

The CPV efficiency under concentration is calculated based on Equation (1) taking into account the concentration ratio of the Fresnel lens [36]:

$$
G^{*}=G \cdot C,
$$

where $G$ from Equation (1) is replaced by $G^{*}$ which repre- sents the modified solar radiation and $C$ is the concentration ratio that includes the optical efficiency of the Fresnel lens $\left(\eta_{\mathrm{FL}}=83 \%\right)$ [18]. The average efficiencies obtained for CPVs based on Equations (1) and (2) were 32.3\% for WAC, 31.4\% for WoAC, and $30.8 \%$ for WGS.

One can observe in Figure 7 that the electric powers generated by the CPVs have decreased from WAC to WoAS and WGS configurations. This happened because their temperatures have increased (Figure 8).

For the WGS configuration, the concentration ratio was modified to 33 suns for the last part of the measurements and, as can be seen from Figure 7, the electric power of the CPVs increased to $4.06 \mathrm{~W}$ from $3.09 \mathrm{~W}$ (31.4\%). At the same time, the temperature of the CPVs increased by $6^{\circ} \mathrm{C}$ (Figure 8).

3.2. TEG Analysis. The TEG I-V characteristics in concentrated sunlight were measured in the same manner as for CPVs using another available channel of the NI cRIO platform and the EL. In Figure 10, the I-V and P-V characteristics obtained for the TEG array are shown. The temperature difference between the TEG sides was $25^{\circ} \mathrm{C}$, and the irradiance was 25 suns. Based on the I-V characteristic slope, the TEG resistance could be calculated (considering that the four used TEGs are connected in series) and the obtained value is $1.2 \Omega$ which is comparable with the results obtained in [37]. At 25-sun concentration ratio, the maximum electric power obtained from the TEG was $120 \mathrm{~mW}$ in WGS configuration, having the temperature difference of $26^{\circ} \mathrm{C}$. The electrical efficiency of the TEGs can be calculated using the following equation $[38,39]$ :

$$
\eta_{\mathrm{TEG}}=\frac{P_{\max }}{G^{* *} \cdot A_{\mathrm{TEG}}} 100 \%,
$$

where $\eta_{\text {TEG }}$ is the TEG's electrical efficiency, $A_{\text {TEG }}$ is the TEG's array area, and $G^{* *}=G^{*} C^{\prime}$ is the irradiance for TEGs, where the concentration ratio includes also the CPV's electric conversion efficiency, $C^{\prime}=C \cdot\left(1-\eta_{\mathrm{CPV}} / 100\right)$. Even if the exposed surfaces have different reflectivity, for comparison we considered for all three cases the same active area of $16 \mathrm{~cm}^{2}$, without considering the surface reflectivity. The electrical powers generated by the TEGs and the temperature differences between TEG sides in the three configurations are shown in Figures 11 and 12. The average efficiency obtained for 25-sun concentration ratio based on Equation (3) was $0.120 \%$ for WAC, $0.26 \%$ for WoAC, and $0.44 \%$ for WGS.

When the concentration ration was fixed at 33 suns, the maximum electric power generated by the TEG array was $170 \mathrm{~mW}$ at a temperature difference of $30.5^{\circ} \mathrm{C}$. In this case, the TEG efficiency reached $0.45 \%$.

3.3. STC Analysis. To characterize the STC, the water inlet and outlet temperatures and the water flow rate were measured. The difference between the two temperatures was calculated (Figure 13).

The average water temperature difference between the inlet and outlet of the STC at a $0.41 / \mathrm{min}$ water flow rate was $1^{\circ} \mathrm{C}$ for WAC, $1.5^{\circ} \mathrm{C}$ for WoAC, and $1.9^{\circ} \mathrm{C}$ for WGS. 


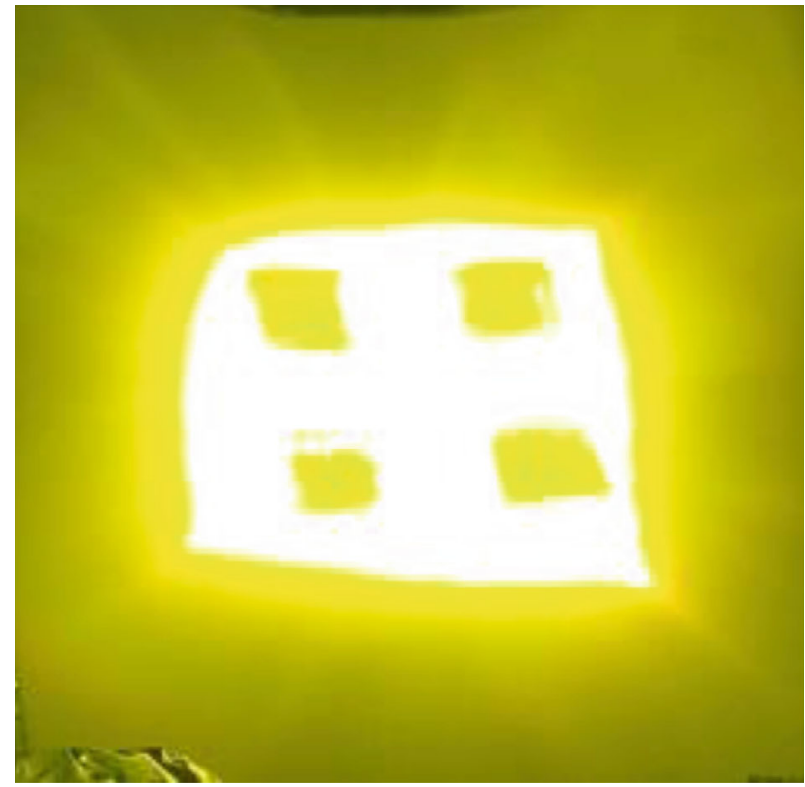

(a)

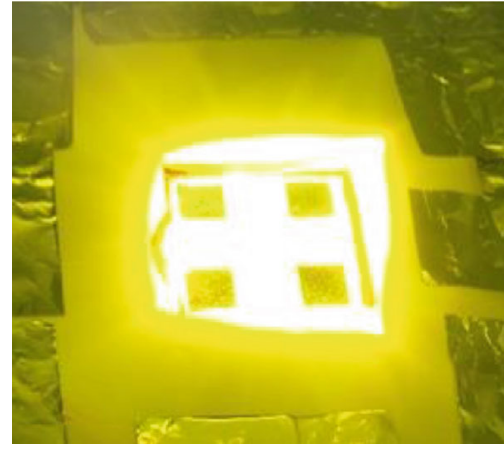

(b)

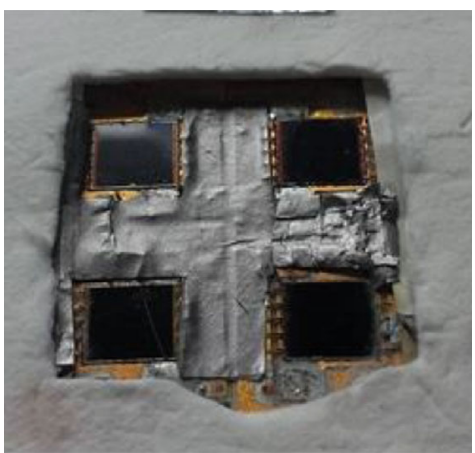

(c)

FIGURE 5: The tested configurations of HS: (a) with alumina cross; (b) without alumina cross; (c) with graphite sheet.

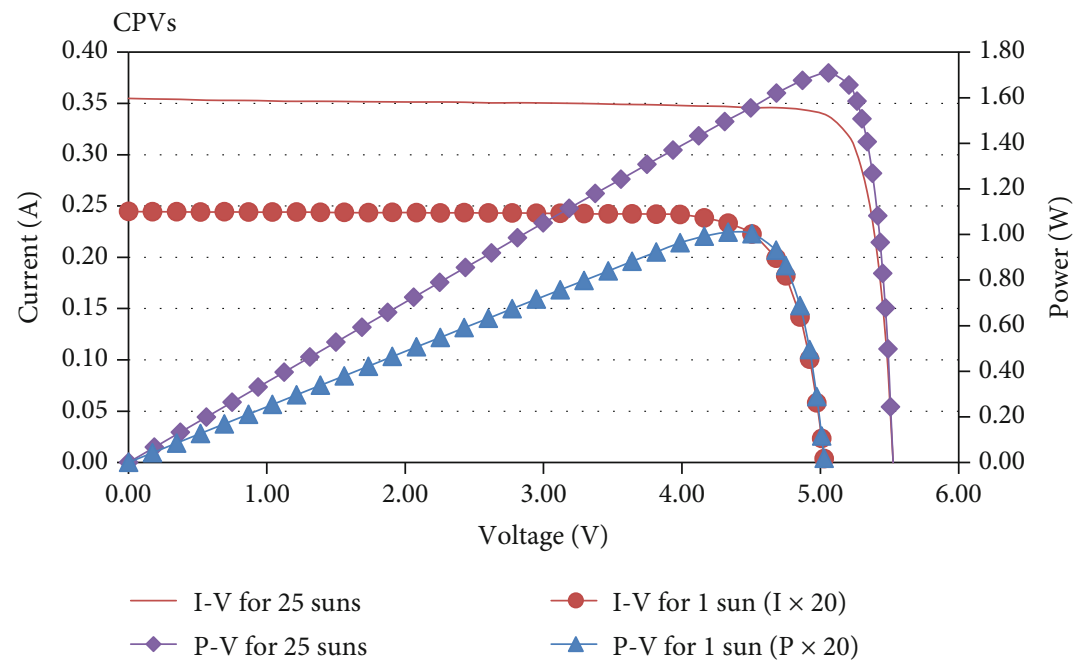

FIgURE 6: The I-V and P-V characteristics in concentrated and nonconcentrated sunlight for CPVs. 


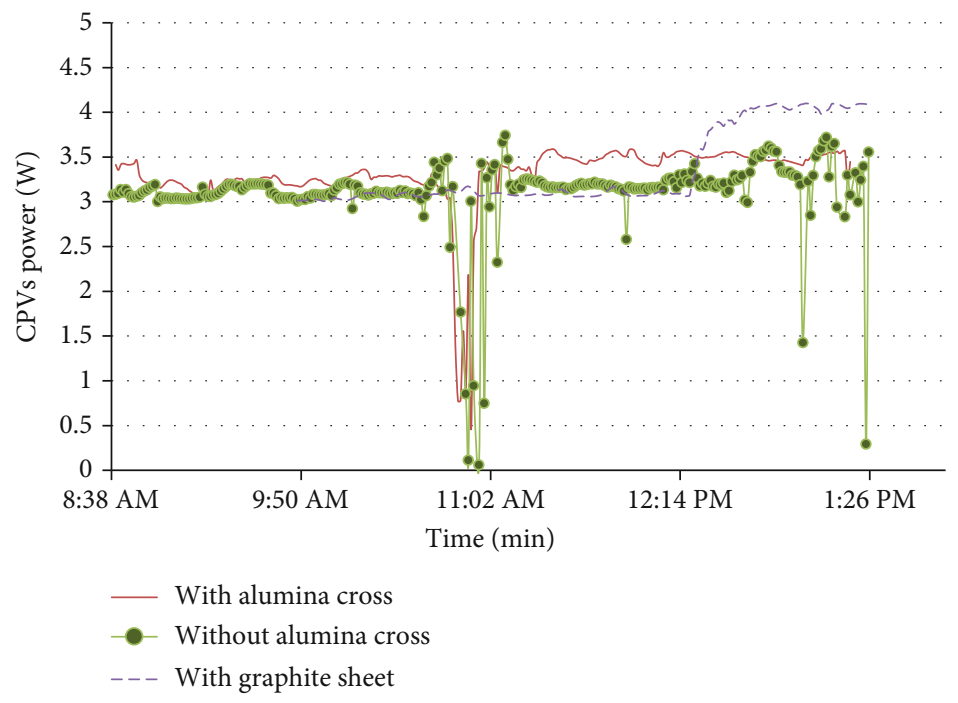

Figure 7: The CPV electric power.

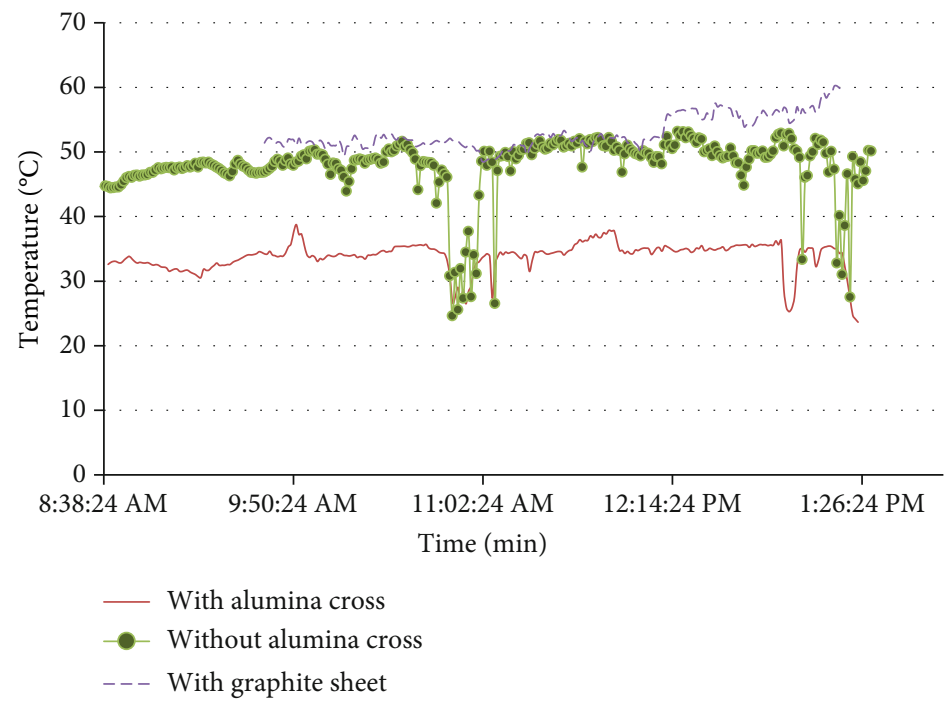

Figure 8: The CPV temperature.

The thermal efficiency of the STC can be calculated based on the following equation [38]:

$$
\eta_{\mathrm{STC}}=\frac{\dot{Q_{W}}}{G^{* * *} \cdot A_{\mathrm{STC}}} 100 \%,
$$

where $\eta_{\mathrm{STC}}$ is the STC thermal efficiency, $A_{\mathrm{STC}}$ is the STC area, $G^{* * *}=G^{*} C^{\prime \prime}$ is the irradiance for STC, where the concentration ratio includes also the CPV's and TEG's electric conversion efficiencies, $C^{\prime \prime}=C \cdot\left(1-\eta_{\mathrm{CPV}} / 100-\eta_{\mathrm{TEG}} / 100\right)$, and $\dot{Q}_{W}$ is the heat transfer rate that is calculated with the following equation:

$$
\dot{Q_{W}}=\dot{m} c_{P} \Delta T,
$$

where $\dot{m}$ is the water flow-rate, $c_{p}$ is the water specific heat capacity, and $\Delta T=T_{\text {out }}-T_{\text {in }}$ is the temperature difference between water outlet and inlet of the STC. Based on Equation (4), the STC efficiency was calculated for the three configurations: $26.3 \%$ for WAC, $35.7 \%$ for WoAC, and $52.0 \%$ for WGS.

For short periods of time, the water flow rate was modified in order to observe the effect in the STC efficiency (Figure 13 marked with red circles). At a $0.561 / \mathrm{min}$ water flow rate, the efficiency was $52.7 \%$, and at $0.31 / \mathrm{min}$, the efficiency dropped to $51.8 \%$. This confirms that the water flow rate can have an important effect on the STC thermal efficiency [19]. Considering this setup in one hour, the temperature of 24 liters of water could be increased with $\sim 2^{\circ} \mathrm{C}$. If the system is multiplied by 5 times in 8 hours, $1 \mathrm{~m}^{3}$ of water could be heated increasing its temperature with $\sim 2^{\circ} \mathrm{C}$. This 


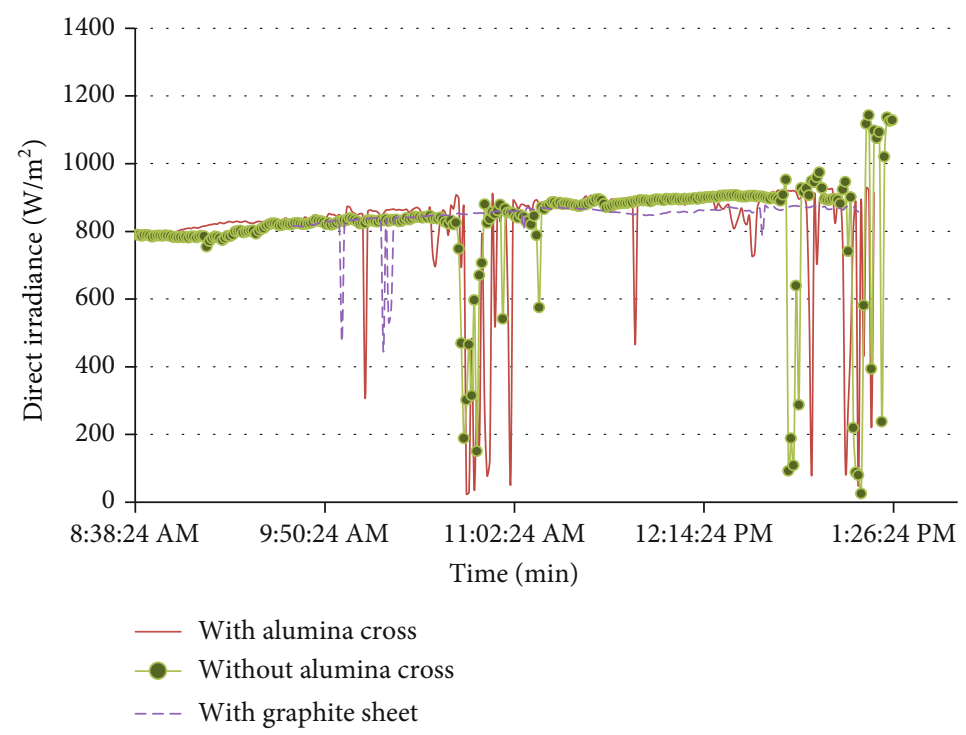

FIgURE 9: The direct sun irradiance during the HS study.

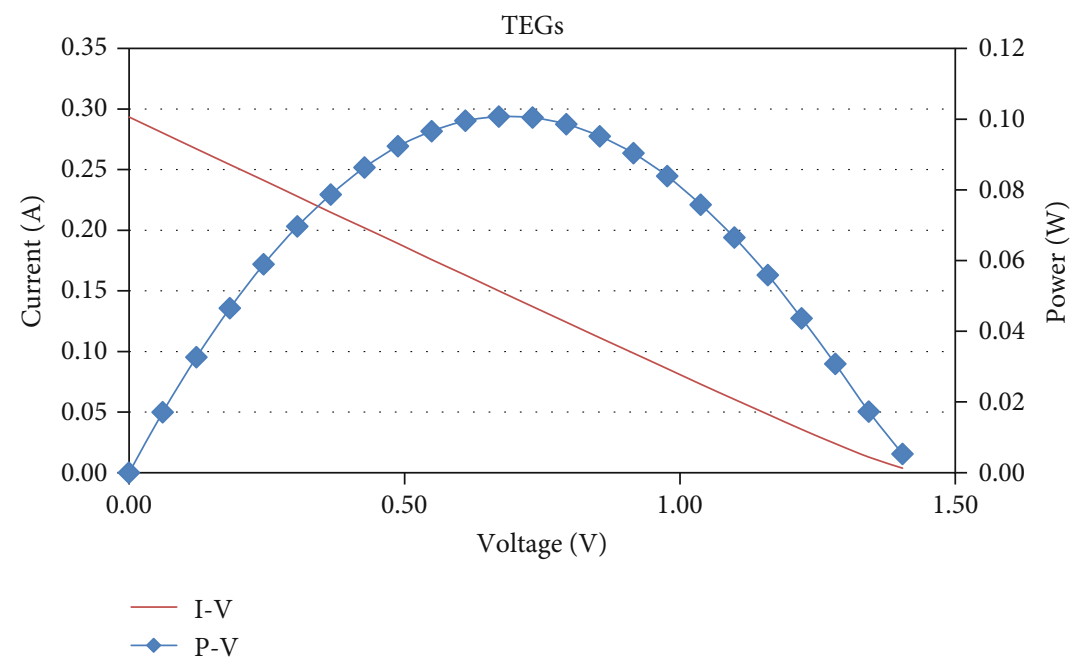

Figure 10: The I-V and P-V characteristics of TEGs in concentrated sunlight ( 25 suns, at $\left.\Delta T=25^{\circ} \mathrm{C}\right)$.

indicates that using the HS with STC can be useful for increasing water temperature for a small swimming pool.

3.4. Discussions. The efficiency results analysed for CPVs, TEGs, and STC are shown in Table 2.

For the efficiency calculus of the HS components, $C_{\text {used }}$ concentration ration was used due to the fact that the incident irradiance is absorbed by each component (CPVs and TEGs) and transferred to the next component minus what is converted into electricity. One can observe in Table 2 that the CPV efficiency has decreased from WAC to WoAS and to WGS configurations as a consequence of their temperatures' increase (Figure 8). This increase in temperature conducts to raising the efficiency of the TEGs and STC. In the WGS configuration, the CPV efficiency decreases once with the increase in concentration ratio. According to the used CPV datasheet [32], their efficiency should increase once with the concentration ratio (until 500 suns), but from Table 2, one can observe that it decreases slowly. This can be explained by the increasing of their temperatures with $6^{\circ} \mathrm{C}$, but also by the uniform breaking and chromatic aberration that increase when the illumination spot becomes equal to the system active area. In [40], it is shown that the fill factor of the CPVs and also their efficiency are affected by the chromatic aberration created by the Fresnel lens.

A CPV/TEG HS using a water cooled heat sink was studied in our previous paper [28]. The efficiency of the CPV shows a decreasing behaviour when the irradiance was increased. The efficiency variations reported in the paper are between $35.33 \%$ and $23.02 \%$ for an irradiance variation between 8 and 37 suns. The reported efficiency of the CPV at 25 suns is $27 \%$. A similar CPV efficiency has been reported [30]. Comparing with the results obtained in this paper, it can be observed that there is $\sim 5 \%$ difference. This can be explained through the spectrum used (in the cited paper, a solar simulator was used), but high influence in this 


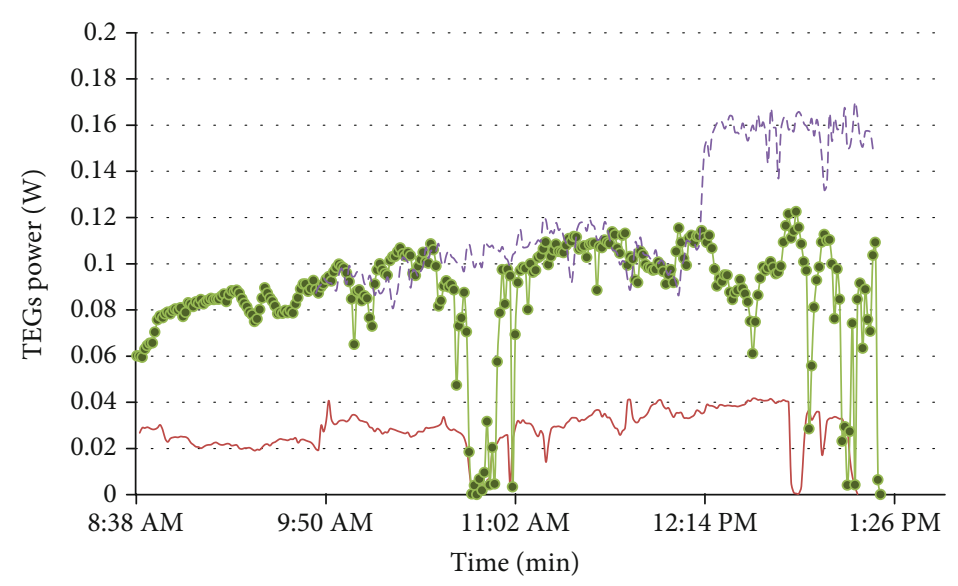

—- With alumina cross
-- Without alumina cross
- - - With graphite sheet

FIgURE 11: The TEG electric power.

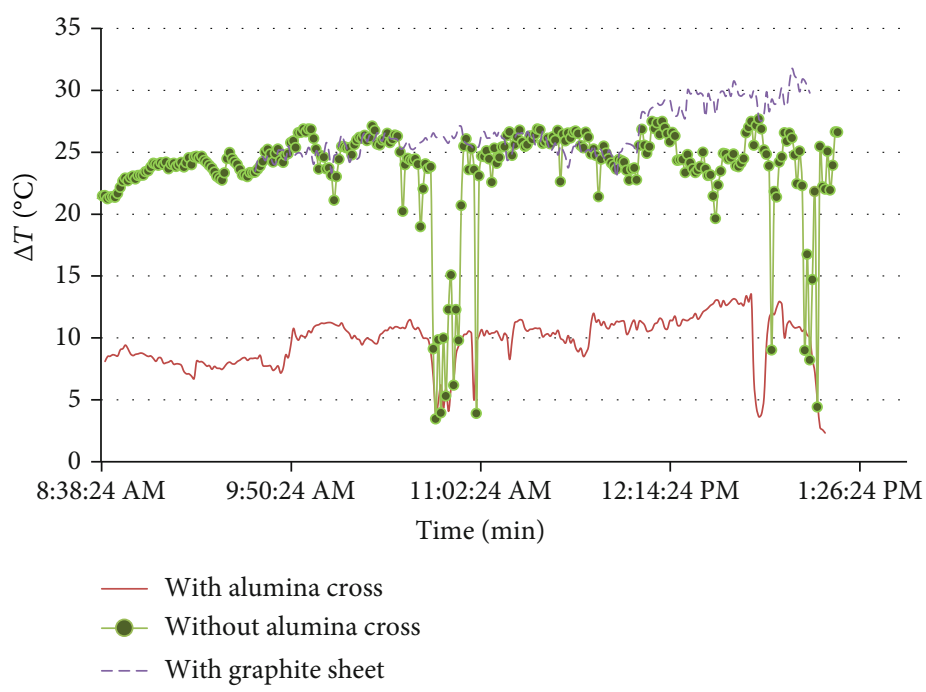

FIgURE 12: The temperature differences between TEG sides.

difference is given by the temperature. In the cited paper, the reported $\mathrm{CPV}$ temperature overpasses $100^{\circ} \mathrm{C}$, while in our case, the temperature is $\sim 35^{\circ} \mathrm{C}$ for the first case and $\sim 50^{\circ} \mathrm{C}$ for the last two cases. These differences are explained by the differences in testing conditions: irradiance spectrum (Xe lamps were used for solar simulator versus sunlight) and enclosed room versus free space.

The contribution of the TEG is small on the overall electrical energy generation, having a maximum power of $0.12 \mathrm{~W}$ in the WGS. The ratio of the average maximum powers generated by the TEG and CPV is shown in Figure 14. This ratio increases with the increase of absorbed heat and also with the solar concentration [28], starting from $0.9 \%$ up to $4 \%$. The WGS2 is the WGS case with the concentration of 33 suns. Although the available commercial TEG efficiency is very small, a new TEG is reported in recent literature with an efficiency of 7.4\% [41]. These high efficiencies of the proposed TEG are obtained at high temperature (around of $600^{\circ} \mathrm{C}$ ).
At low temperature, the efficiency of the TEGs is smaller being in the range of $1-2 \%$. In [42], it is shown that the efficiency for the TEGs with figure of merit, $\mathrm{ZT}=2$ at $\Delta T=25$ ${ }^{\circ} \mathrm{C}$, is around $2 \%$. By using such TEGs, its contribution will significantly increase the overall efficiency of the HS. In our case, considering the WGS case, the TEG contribution will increase more than 4.5 times. This means that the power generated by the TEG could be around $540 \mathrm{~mW}$, which represents $17 \%$ from the CPV total power generation.

By using the graphite sheet, it was shown that the performance of the TEG and STC increases, in the detriment of the CPV. In our setup, from a $16 \mathrm{~cm}^{2}$ exposed surface, only $4 \mathrm{~cm}^{2}$ are active. The CPVs are very good absorbers, and increasing their density on the exposed surface could increase the performance of the HS by increasing the electrical conversion of the CPV, but also due to more heat generated by CPVs and used by TEG and STC. A custom module or module like [43] could be used to increase the CPV density. 


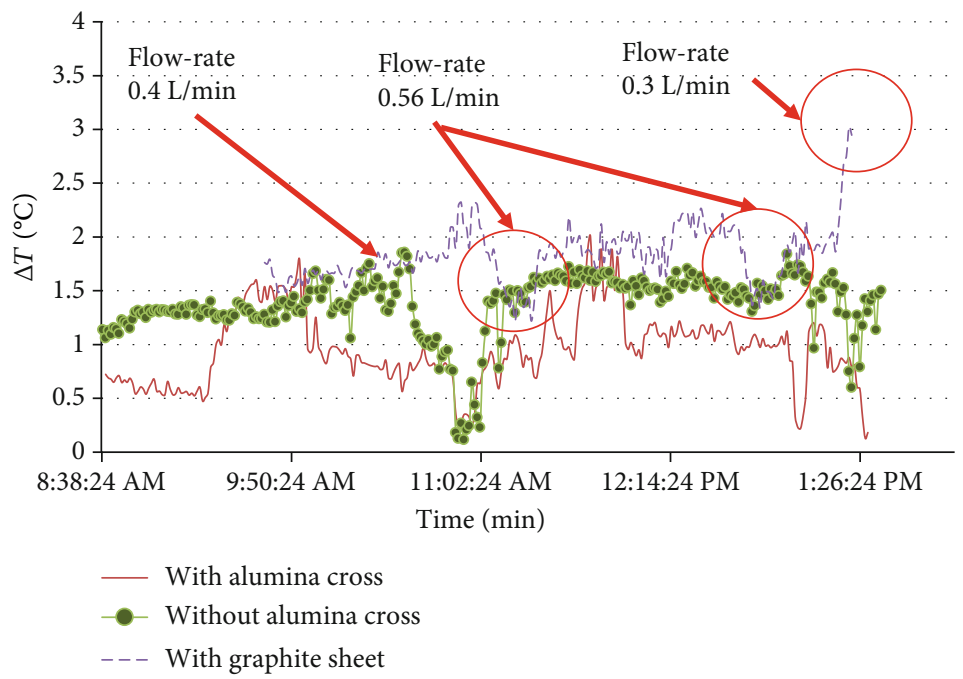

FIgURE 13: The variation of the temperature difference for STC.

TABle 2: The efficiencies of the HS components in the three cases considered.

\begin{tabular}{|c|c|c|c|c|c|}
\hline \multirow{2}{*}{ HS components } & \multirow{2}{*}{$C$ (sun) } & \multirow{2}{*}{$C_{\text {used }}(\operatorname{sun})$} & \multicolumn{3}{|c|}{ Efficiency (\%) } \\
\hline & & & WAS & WoAS & WGS \\
\hline \multirow{2}{*}{ CPVs } & 25 & \multirow{2}{*}{$C$} & 32.32 & 31.37 & 30.81 \\
\hline & 33 & & - & - & 30.70 \\
\hline \multirow{2}{*}{ TEGs } & 25 & \multirow{2}{*}{$C^{\prime}=C \cdot\left(1-\eta_{\mathrm{CPV}} / 100\right)$} & 0.12 & 0.26 & 0.44 \\
\hline & 33 & & - & - & 0.45 \\
\hline \multirow{2}{*}{ STC } & 25 & \multirow{2}{*}{$C^{\prime}=C \cdot\left(1-\eta_{\mathrm{CPV}} / 100-\eta_{\mathrm{TEG}} / 100\right)$} & 26.32 & 35.69 & 52.03 \\
\hline & 33 & & - & - & 54.21 \\
\hline
\end{tabular}

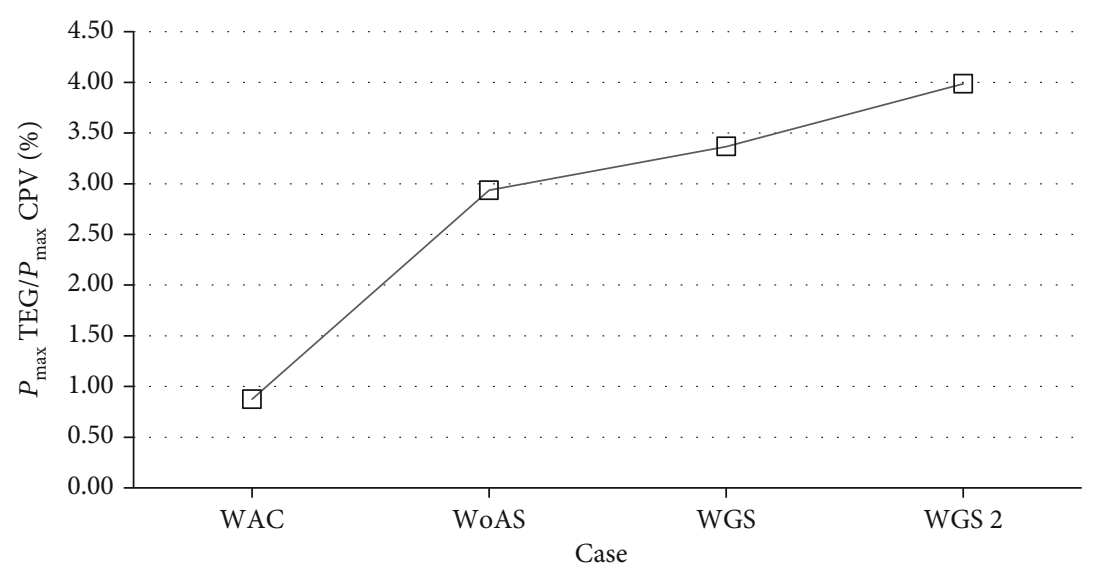

FIGURE 14: Ratio between the maximum power of the TEG and CPV versus considered cases.

\section{Conclusions}

In this paper, a HS having a CPV/TEG/STC structure was studied at 25-sun concentration ratio. Three setups were considered for the exposed surface of the HS to the irradiance: the CPV active area, the support CPV area, and the support CPV area covered with a graphite layer. Based on this particular setup of the HS, the analysis of the effect of increasing the heat absorbance over the HS components was successfully done. It was noticed that due to the more heat absor- bance in the three studied cases, the CPV efficiency decreases from $32.3 \%$ to $30.8 \%$, while the efficiency of the TEGs increases from $0.12 \%$ to $0.44 \%$, and for the STC, it increases from $26.3 \%$ to $52.0 \%$. Using a heat absorbing material on the exposed area increased the electric and thermal power generated by the TEGs and STC, but decreased the electrical power generated by the CPVs.

Increasing the concentration ratio, the efficiency of the CPVs has shown a small decrease due to the increase of their temperature but the efficiency of the other two components, 
TEGs and STC, showed a small increase. We found that the small flow rate variation of the water affects the efficiency of the STC.

Through this study, we showed that the exposed surface absorbance should be considered for HS design in order to have better overall efficiency. In the same time, the experiments in real working conditions should be performed to prove the HS performances. The advantage of hybrid systems is as follows: increased efficiency of the CPVs by a drop in their temperature and energy cogeneration (electrical by TEG and thermal by STC). These performances of the HS could be improved by using the TEGs with high performances and optimizing the surface reflectance of the CPV support surface.

Based on the three setups that were studied in this paper, it can be concluded that

(i) if the important part is electrical energy generation, then the first case should be used, due to the low temperature reached by the CPVs

(ii) if the thermal energy is also important, then the third case should be used in order to increase the STC efficiency. In this case, the electrical cogeneration of the TEG is increased to the detriment of the CPV generation. In this configuration, the thermal energy is increased and the proposed HS could be used as domestic system for heating the water of small swimming pool

Further works will be focused on studying the effect of increasing the density of the CPVs over the HS performances combined with concentration ratio variation and long-term monitor. The customization and the CPV density increase will strongly affect the costs for the HS. Therefore, the economic aspects represent another further study to be undertaken. Another direction of the further research is to find through simulations and experiments the optimal structure and dimensions for domestic applications, like water heating for a small swimming pool.

\section{Data Availability}

The datasets used in the present study are available from the corresponding author upon reasonable request.

\section{Conflicts of Interest}

The authors declare that there is no conflict of interest regarding the publication of this paper.

\section{References}

[1] M. A. Green, Y. Hishikawa, E. D. Dunlop et al., "Solar cell efficiency tables (version 53)," Progress in Photovoltaics: Research and Applications, vol. 27, no. 1, pp. 3-12, 2019.

[2] R. Santbergen and R. J. C. van Zolingen, "The absorption factor of crystalline silicon PV cells: a numerical and experimental study," Solar Energy Materials \& Solar Cells, vol. 92, no. 4, pp. 432-444, 2008.
[3] J. Siecker, K. Kusakana, and B. P. Numbi, "A review of solar photovoltaic systems cooling technologies," Renewable and Sustainable Energy Reviews, vol. 79, pp. 192-203, 2017.

[4] D. T. Cotfas and P. A. Cotfas, "Multi concept methods to enhance photovoltaic systems efficiency," International Journal of Photoenergy, vol. 2019, 14 pages, 2019.

[5] K. A. Moharram, M. S. Abd-Elhady, H. A. Kandil, and H. ElSherif, "Enhancing the performance of photovoltaic panels by water cooling," Ain Shams Engineering Journal, vol. 4, no. 4, pp. 869-877, 2013.

[6] A. A. Alzaabi, N. K. Badawiyeh, H. O. Hantoush, and A. K. Hamid, "Electrical/thermal performance of hybrid PV/T system in Sharjah, UAE," International Journal of Smart Grid and Clean Energy, vol. 3, pp. 385-389, 2014.

[7] C. Good, "Environmental impact assessments of hybrid photovoltaic-thermal (PV/T) systems," Renewable and Sustainable Energy Reviews, vol. 55, pp. 234-239, 2015.

[8] S. Mehrotra, P. Rawat, M. Debbarma, and K. Sudhakar, "Performance of a solar panel with water immersion cooling technique," International Journal of Science, Environment and Technology, vol. 3, pp. 1161-1172, 2014.

[9] R. Mazón-Hernández, J. R. García-Cascales, F. Vera-García, A. S. Káiser, and B. Zamora, "Improving the electrical parameters of a photovoltaic panel by means of an induced or forced air stream," International Journal of Photoenergy, vol. 2013, 10 pages, 2013.

[10] C. G. Popovici, S. V. Hudișteanu, T. D. Mateescu, and N.C. Cherecheş, "Efficiency improvement of photovoltaic panels by using air cooled heat sinks," Energy Procedia, vol. 85, pp. 425-432, 2016.

[11] W. Pang, Y. Liu, S. Shao, and X. Gao, "Empirical study on thermal performance through separating impacts from a hybrid PV/TE system design integrating heat sink," International Communications in Heat and Mass Transfer, vol. 60, pp. 912, 2015.

[12] S. Nižetić, I. Marinić-Kragić, F. Grubišić-Čabo, A. M. Papadopoulos, and G. Xie, "Analysis of novel passive cooling strategies for free-standing silicon photovoltaic panels," Journal of Thermal Analysis and Calorimetry, vol. 141, no. 1, pp. 163$175,2020$.

[13] F. G. Čabo, S. Nižetić, E. Giama, and A. Papadopoulos, "Techno-economic and environmental evaluation of passive cooled photovoltaic systems in Mediterranean climate conditions," Applied Thermal Engineering, vol. 169, article 114947, 2020.

[14] D. T. Cotfas, P. A. Cotfas, D. Ciobanu, and O. M. Machidon, "Characterization of photovoltaic-thermoelectric-solar collector hybrid systems in natural sunlight conditions," Journal of Energy Engineering, vol. 143, no. 6, article 04017055, 2017.

[15] G. Li, X. Chen, and Y. Jin, "Analysis of the primary constraint conditions of an efficient photovoltaic-thermoelectric hybrid system," Energies, vol. 10, no. 1, p. 20, 2017.

[16] A. Rezania and L. A. Rosendahl, "Feasibility and parametric evaluation of hybrid concentrated photovoltaicthermoelectric system," Applied Energy, vol. 187, pp. 380389, 2017.

[17] T. H. Kil, S. Kim, D. H. Jeong et al., "A highly-efficient, concentrating-photovoltaic/thermoelectric hybrid generator," Nano Energy, vol. 37, pp. 242-247, 2017.

[18] T. Liao, B. Lin, and Z. Yang, "Performance characteristics of a low concentrated photovoltaic-thermoelectric hybrid power 
generation device," International Journal of Thermal Sciences, vol. 77, pp. 158-164, 2014.

[19] F. Saeedi, F. Sarhaddi, and A. Behzadmehr, "Optimization of a PV/T (photovoltaic/thermal) active solar still," Energy, vol. 87, pp. 142-152, 2015.

[20] M. George, A. K. Pandey, N. A. Rahim, V. V. Tyagi, S. Shahabuddin, and R. Saidur, "Concentrated photovoltaic thermal systems: a component-by-component view on the developments in the design, heat transfer medium and applications," Energy Conversion and Management, vol. 186, pp. 15-41, 2019.

[21] W. T. Xie, Y. J. Dai, R. Z. Wang, and K. Sumathy, "Concentrated solar energy applications using Fresnel lenses: a review," Renewable and Sustainable Energy Reviews, vol. 15, no. 6, pp. 2588-2606, 2011.

[22] M. Tian, Y. Su, H. Zheng, G. Pei, G. Li, and S. Riffat, "A review on the recent research progress in the compound parabolic concentrator (CPC) for solar energy applications," Renewable and Sustainable Energy Reviews, vol. 82, pp. 1272-1296, 2018.

[23] X. Ju, C. Xu, X. Han, X. Du, G. Wei, and Y. Yang, "A review of the concentrated photovoltaic/thermal (CPVT) hybrid solar systems based on the spectral beam splitting technology," Applied Energy, vol. 187, pp. 534-563, 2017.

[24] F. Yazdanifard, E. Ebrahimnia-Bajestan, and M. Ameri, "Performance of a parabolic trough concentrating photovoltaic/thermal system: effects of flow regime, design parameters, and using nanofluids," Energy Conversion and Management, vol. 148, pp. 1265-1277, 2017.

[25] A. Riahi, A. B. H. Ali, A. Fadhel, A. Guizani, and M. Balghouthi, "Performance investigation of a concentrating photovoltaic thermal hybrid solar system combined with thermoelectric generators," Energy Conversion and Management, vol. 205, article 112377, 2020.

[26] S. Mahmoudinezhad, S. A. Atouei, P. A. Cotfas, D. T. Cotfas, L. A. Rosendahl, and A. Rezania, "Experimental and numerical study on the transient behavior of multi-junction solar cellthermoelectric generator hybrid system," Energy Conversion and Management, vol. 184, pp. 448-455, 2019.

[27] A. Mohammadnia, A. Rezania, B. M. Ziapour, F. Sedaghati, and L. Rosendahl, "Hybrid energy harvesting system to maximize power generation from solar energy," Energy Conversion and Management, vol. 205, p. 112352, 2020.

[28] S. Mahmoudinezhad, A. Rezania, D. T. Cotfas, P. A. Cotfas, and L. A. Rosendahl, "Experimental and numerical investigation of hybrid concentrated photovoltaic - Thermoelectric module under low solar concentration," Energy, vol. 159, pp. 1123-1131, 2018.

[29] D. Yang and H. Yin, "Energy conversion efficiency of a novel hybrid solar system for photovoltaic, thermoelectric, and heat utilization," IEEE Transactions on Energy Conversion, vol. 26, no. 2, pp. 662-670, 2011.

[30] D. T. Cotfas, P. A. Cotfas, L. Floroian, and D. I. Floroian, "Study of combined photovoltaic cell/thermoelectric element/solar collector in medium concentrated light," in 2017 International Conference on Optimization of Electrical and Electronic Equipment (OPTIM) \& 2017 Intl Aegean Conference on Electrical Machines and Power Electronics (ACEMP), pp. 747752, Brasov, Romania, 2017.

[31] P. Pérez-Higueras, E. Muñoz, G. Almonacid, and P. G. Vidal, "High Concentrator PhotoVoltaics efficiencies: Present status and forecast," Renewable and Sustainable Energy Reviews, vol. 15, no. 4, pp. 1810-1815, 2011.
[32] 2020, https://solaerotech.com/wp-content/uploads/2018/03/ CTJ-Datasheet.pdf.

[ 33 ] $2020, \mathrm{https}: / / \mathrm{www} . \mathrm{tme} . \mathrm{eu} / \mathrm{Document} /$ f90b783c096cf8ceee627b2a275a42d4/pm-40x40-89.pdf.

[34] M. Victoria, S. Askins, R. Herrero et al., "Measuring primary lens efficiency: a proposal for standardization," in 12th International Conference on Concentrator Photovoltaic Systems (CPV-12), p. 120001, Freiburg, Germany, 2016.

[35] P. A. Cotfas, D. T. Cotfas, C. Gerigan, and O. M. Machidon, "System design to study hybrid systems in concentrated light using Fresnel lens," in 2017 International Conference on Optimization of Electrical and Electronic Equipment (OPTIM) \& 2017 Intl Aegean Conference on Electrical Machines and Power Electronics (ACEMP), pp. 753-758, Brasov, Romania, 2017.

[36] F. Karimi, H. Xu, Z. Wang, J. Chen, and M. Yang, "Experimental study of a concentrated PV/T system using linear Fresnel lens," Energy, vol. 123, pp. 402-412, 2017.

[37] H. Terzioglu, "Analysis of effect factors on thermoelectric generator using Taguchi method," Measurement, vol. 149, p. 106992, 2020.

[38] M. H. Nia, A. A. Nejad, A. M. Goudarzi, M. Valizadeh, and P. Samadian, "Cogeneration solar system using thermoelectric module and Fresnel lens," Energy Conversion and Management, vol. 84, pp. 305-310, 2014.

[39] M. H. Shareef, A. Sajid, A. A. Majeed, and M. A. B. Adnan, "Efficiency calculation of a thermoelectric generator," International Journal of Science and Research, vol. 5, no. 7, pp. 15201522, 2016.

[40] M. Steiner, G. Siefer, T. Schmidt, M. Wiesenfarth, F. Dimroth, and A. W. Bett, " $43 \%$ sunlight to electricity conversion efficiency using CPV," IEEE Journal of Photovoltaics, vol. 6, no. 4, pp. 1020-1024, 2016.

[41] D. Kraemer, Q. Jie, K. McEnaney et al., "Concentrating solar thermoelectric generators with a peak efficiency of $7.4 \%$," Nature Energy, vol. 1, no. 11, article 16153, 2016.

[42] D. Champier, "Thermoelectric generators: a review of applications," Energy Conversion and Management, vol. 140, pp. 167$181,2017$.

[43] 2020, http://www.azurspace.com/index.php/en/products/ products-cpv/cpv-dense-array-module. 